\title{
18 THE USES AND ABUSES OF EVALUATIVE CRITERIA FOR QUALITATIVE RESEARCH METHODS
}

\author{
Richard Baskerville \\ Georgia State University \\ U.S.A. \\ Steve Sawyer \\ Syracuse University \\ U.S.A. \\ Eileen Trauth \\ Northeastern University \\ U.S.A. \\ Duane Truex \\ Georgia State University \\ U.S.A.

\section{Cathy Urquhart University of the Sunshine Coast Australia}

The focus of this panel is on the impact of recent trends toward the establishment of quality criteria for evaluating qualitative information systems research. Advances in the use of qualitative and intensive research methods in information systems have raised 
debates about the methods for the evaluation of this form of research. Such criteria are not new in the general social science literature (e.g., Gummesson 1988; Kirk and Miller 1986; Yin 1989). However, these criteria have been more generally directed toward objective forms of qualitative research than toward interpretive forms of qualitative research. More recent work within the organizational (Golden-Biddle and Locke 1993) and information systems fields (Klein and Myers 1999) may provide general criteria for evaluating interpretive research. In addressing the issues that arise from the availability of these criteria, the panel will be structured with approximately half the time period dedicated to an opening discussion by the panelists, followed by an open forum debate engaging the audience to occupy the remaining half of the time period.

Richard Baskerville will open the panel with a brief overview of the current state of criteria used for evaluating qualitative research in information systems. Following this overview, Baskerville will summarize the advantages and disadvantages of criteria with regard to the quality goals of journals and conference venues.

Steve Sawyer will discuss how quality criteria affect the use of multi-method approaches to IS/IT research. Multi-method approaches often mean combining data collection and analysis techniques which have differing philosophical and analytic traditions (such as a combination of surveys and fieldwork). Further, while there is continual encouragement to employ multiple methods, there are relatively few studies of this nature in the IS/IT literature. Drawing on an ongoing multi-method study as an example (and not as an exemplar!), he will outline how general guidelines for conducting multi-method studies are enacted. He will also discuss what sorts of issues and implications arise from design decisions driven, in part, by the recognition of guidelines.

Eileen Trauth will consider the debate from the perspective of a researcher. She will discuss the practical consequences of having an established set of quality criteria on the conduct of qualitative (and in particular, interpretive) research. She will present an argument in favor of having such criteria. Her arguments will focus on the politics of publishing (both journal articles and books), faculty reward systems, and the allocation of energy and effort (on the research itself or on justifying it). She will express the viewpoint that establishing criteria need not be a constraining act but, rather, the beginning of a dialectical process which will constantly change (and hopefully improve) the conduct of qualitative research.

Duane Truex will review the impact of qualitative criteria on the emergence of the IS field. In so doing, he will be taking the position of the loyal opposition and will offer a provocative and cautionary deconstruction of a standard and thus challenge the position that a semblance of fixed standards are required at all. He will begin with a brief genealogy of the discourse in which qualitative research was introduced and finally gained acceptance in our research community. He will then offer a suggestion as to how the field might concern itself more with the social and continuous process of standardizing rather than adjudicating strictures. That is, the question of standards might be better viewed as a continuous and emergent language game.

Cathy Urquhart will discuss the principles from the perspective of having recently applied them to evaluate a recent project that encompassed hermeneutic study of texts and also used grounded theory. In particular, she will discuss the utility of such principles, how they represent an important debating point, and whether indeed such 
principles can be applied without becoming an orthodoxy that goes against the pluralistic nature of interpretive research.

\section{References}

Golden-Biddle, K., and Locke, K. “Appealing Work: An Investigation of How Ethnographic Texts Convince," Organization Science (4:4), 1993, pp. 595-616.

Gummesson, E. Qualitative Methods in Management Research. Lund, Sweden: Studentlitterature Chartwell-Bratt, 1988.

Kirk, J., and Miller, M. L. Reliability and Validity in Qualitative Research. Newbury Park, CA: Sage, 1986.

Klein, H. K., and Myers, M. D. “A Set of Principles for Conducting and Evaluating Interpretive Field Studies in Information Systems," MIS Quarterly (23:1), March 1999, pp. 67-93.

Yin, R. Case Study Research: Design and Methods. Newbury Park, CA: Sage, 1989. 